|| ISSN(online): 2589-8698 || ISSN(print): 2589-868X || International Journal of Medical and Biomedical Studies

Available Online at www.ijmbs.info

Volume 3, Issue 2; February: 2019; Page No. 82-86

PubMed (National Library of Medicine ID: 101738825)

Index Copernicus Value 2017: 40.03

\title{
CERVICAL PAP SMEAR STUDY IN A TERTIARY CARE TEACHING HOSPITAL
}

Mohammad Khushnood ${ }^{1}$, Priya Vijaykumar Gameti ${ }^{2 *}$, Anisha Rajani ${ }^{3}$, Mala Jain ${ }^{4}$

${ }^{1}$ Senior Demonstrator, Government Medical College, Dungarpur, Rajasthan, India.

${ }^{2}$ Assistant Professor, Government Medical College, Dungarpur, Rajasthan, India.

${ }^{3}$ Senior Resident, Department of Pathology, GMC, Surat, India.

${ }^{4}$ Assistant Professor, Government Medical College, Dungarpur, Rajasthan, India

Article Info: Received 25 January 2019; Accepted 16 February. 2019

Cite this article as: Khushnood, M., Gameti, P. V., Rajani, A., \& Jain, M. (2019). CERVICAL PAP SMEAR STUDY IN A TERTIARY CARE TEACHING HOSPITAL. International Journal of Medical and Biomedical Studies, 3(2).

DOI: https://doi.org/10.32553/ijmbs.v3i2.100

Address for Correspondence: Dr. Priya Vijaykumar Gameti, Assistant Professor, Government Medical College, Dungarpur, Rajasthan

Conflict of interest: No conflict of interest.

\section{Abstract}

Background: Mortality due to cervical cancer is also an indicator of health inequalities, as $86 \%$ of all deaths due to cervical cancer are in developing countries, low- and middle-income countries. Though Pap smear is a routine screening test, the overall sensitivity in detection of high grade squamous intraepithelial lesion (HSIL) is 70 - 80\% .Pap smear is a simple, safe, non-invasive and cost effective method for the detection of pre-cancerous, cancerous and benign lesions of cervix.

Materials and Method: Around 100 cases attending gynecology OPD consented to participate were selected between age 15-60years with complaints. Pap smear was taken and was reported by cytopathologists according to the 2001 Bethesda system. All the data were manually collected and subsequently analyzed.

Results: Maximum number of cases (37\%)were seen in the age group og 31-40 years followed by 41-50 years (29\%)and rest between $21-30$ years (26\%). $8 \%$ cases were seen in the age group of $51-60$ years. NILM was reported in $48 \%$ of cases. Inflammatory smears were seen in $44 \%$ of cases. Two smears were reported as unsatisfactory.02\% of cases was reported as ASCUS.LSIL was reported in $02 \%$ of cases while HSIL were reported in $01 \%$ of cases. Non specific findings were reported in 01 case.

Conclusion: This study proves that PAP stain is a simple, cheap, inexpensive and easy procedure and that using PAP stain cytological screening programs conducted in developing countries can play a major role in reducing mortality and morbidity due to Cancer Cervix.

Keywords: PAP stain, Cervix, Cancer

\section{Introduction:}

Cancer of the cervix is a global health problem, comprises approximately $12 \%$ of all cancers among women globally ${ }^{1}$.According to National Cancer Registry Program of India, cancers of uterine cervix and breast are leading malignancies seen in Indian women ${ }^{2}$.Cervical 
cancer is the most common cause of cancer related deaths among women in developing countries. Mortality due to cervical cancer is also an indicator of health inequalities, as $86 \%$ of all deaths due to cervical cancer are in developing countries, low- and middle-income countries ${ }^{3}$.The Pap test was introduced by George Papanicolaou as a cervical pathology screening test in $1941^{4}$. Cancer of cervix is readily preventable, by early detection and appropriate timely treatment of its precursor lesions by simple Pap screening test. Though Pap smear is a routine screening test, the overall sensitivity in detection of high grade squamous intraepithelial lesion (HSIL) is $70-80 \%^{5}$.Pap smear is a simple, safe, non-invasive and cost effective method for the detection of pre-cancerous, cancerous and benign lesions of cervix 6 .Usually Pap smear screening test is recommended starting around 21 years of age until the age of 65 years. Can be repeated at three years interval ${ }^{7}$.

Materials and methods: This retrospective study was carried out over 1 year at the Department of Pathology, Government Medical College, Dungarpur. Around 100 cases attending gynecology OPD consented to participate were selected between age 15-60years with complaints .A sample was taken from the cervix by rotating a wooden Ayre spatula $360^{\circ}$. The sample was quickly smeared onto a labeled glass slide and fixed with $95 \%$ ethyl alcohol in a jar and stained with Pap stain. Required clinical history of the patients was obtained from the requisition forms and patient's file. All the smears were reported by cytopathologists according to the
2001 Bethesda system. All the data were manually collected and subsequently analyzed.

Inclusion criteria: Age> 21 years.

Exclusion criteria: Unmarried females, pregnant women and already diagnosed cases of cervix carcinoma. Ethical clearance to do this retrospective study.

\section{Observation:}

A total of 100 cases were evaluated the age of the patients varied from 21 to 60 years. Maximum number of cases (37\%)were seen in the age group og 31-40 years followed by 41-50 years (29\%)and rest between $21-30$ years (26\%). $8 \%$ cases were seen in the age group of 51-60 years. Neoplastic lesions were more common in the age group of 41-50 years. Detailed history was taken and evaluated and commonest chief complaint of cases were found to be vaginal discharge (39\%) followed by patients coming for routine PAP (29\%), cases presented with postmenopausal bleed (11\%),asymptomatic cases (06\%), intermenstrual bleeding (05\%), abnormal uterine bleeding (04\%) and 04\% cases presented with something coming out pv. The Bethesda system of reporting (2014) was applied. Among 100 pap smear reports evaluated possibility of malignancy were ruled out in $48 \%$ of cases. Inflammatory smears were seen in $44 \%$ of cases. Two smears were reported as unsatisfactory. $02 \%$ of cases was reported as ASCUS.LSIL was reported in $02 \%$ of cases while HSIL were reported in $01 \%$ of cases. Non specific findings were reported in 01 case.

Table 1: Distribution of patients according to age:

\begin{tabular}{|l|l|l|}
\hline Age group (years) & Number of patients & \% of patients \\
\hline $21-30$ & 26 & 26 \\
\hline $31-40$ & 37 & 37 \\
\hline $41-50$ & 29 & 29 \\
\hline $51-60$ & 08 & 08 \\
\hline Total & 100 & 100 \\
\hline
\end{tabular}


Table 2: Chief complaints of cases:

\begin{tabular}{|l|l|l|}
\hline Complaints & $\begin{array}{l}\text { Number of patients } \\
\text { complaining }\end{array}$ & of patients complaining \\
\hline Asymptomatic & 06 & 06 \\
\hline Vaginal discharge & 39 & 39 \\
\hline Inter menstrual bleeding & 05 & 05 \\
\hline Abnormal uterine bleeding & 04 & 04 \\
\hline Something coming out pv & 04 & 04 \\
\hline Post-menopausal bleed & 11 & 11 \\
\hline Routine PAP smear & 29 & 29 \\
\hline Others & 02 & 02 \\
\hline Total & 100 & 100 \\
\hline
\end{tabular}

Table 3: Cytological findings of PAP stain:

\begin{tabular}{|l|l|l|}
\hline Findings on PAP smear & Number of patients & \% of patients \\
\hline Unsatisfactory & 02 & 02 \\
\hline NILM & 48 & 48 \\
\hline Inflammatory & 44 & 44 \\
\hline Nonspecific findings & 01 & 01 \\
\hline ASCUS & 02 & 02 \\
\hline ASC-H & 0 & 0 \\
\hline LSIL & 02 & 02 \\
\hline HSIL & 01 & 01 \\
\hline SCC & 0 & 0 \\
\hline Others & 0 & 0 \\
\hline Total & 100 & 100 \\
\hline
\end{tabular}

ASCUS - Atypical squamous cells of undetermined significance

ASCH - Atypical squamous cells cannot exclude HSIL

LSIL - Low grade squamous intraepithelial lesion

HSIL - High grade squamous intraepithelial lesion

SCC - Squamous cell carcinoma

NILM - Negative for intraepithelial or malignancy

\section{Discussion:}

The majority cases were seen in between 31-40 years followed by 41-50 years. These findings are similar to findings with other studies .Some variations in data could be due to smaller database of our study. Considering the fact that the common age to develop cervical cancer is between 40 and 50 years and its precursor lesion usually occurs $5-10$ years earlier ${ }^{8}$ and that mass screening should be started as early as possible. From the above finding we conclude that screening by Pap smear should start at the age of 21 years and above; if we catch them early we can prevent further development of cancer. This study determines $48 \%$ cases of negative for any intraepithelial lesion or malignancy with nonspecific inflammation cases as $44 \%$ as the predominant one. P Vijaya et al ${ }^{9}$, Chandni et al ${ }^{10}$, Sunita et $\mathrm{al}^{11}$, Ashok et $\mathrm{al}^{8}$ revealed $04 \%, 86 \%, 88 \%$ and $56 \%$ cases of NILM respectively. Inflammatory smear reports were $40 \%$ in our study while Ashok et al, showeded $32.5 \%$, P.Vijaya Lakshmi et al showed $67 \%$ of 
cases, Mandakini et al $^{12}$ reported $57.48 \%$ of inflammatory cases. Neoplastic lesions .Total of ASCUS,LSIL,HSIL cases in present study are as $2 \%, 2 \%, 1 \%$ respectively .In other studies also these cases varies between $0.3-7 \%$.With the changes in the life styles and demographic profiles in developing countries, noncommunicable diseases are emerging as an important health issues which require appropriate and timely control program before they evolve as an epidemic propagation. Among non communicable diseases Cancer is one of the major causes of morbidity and mortality hence awareness campaigns and large scale Pap screening programmes for women should be propagated especially in the high risk group.

\section{Conclusion:}

It is accepted worldwide that early detection of precancerous lesions of cervix can be done by cytological examination of cervix by Pap smears. If not diagnosed and treated early, these precancerous lesions are likely to progress to invasive Cancers. This study proves that PAP stain is a simple, cheap, inexpensive and easy procedure and that using PAP stain cytological screening programs conducted in developing countries can play a major role in reducing mortality and morbidity due to Cancer Cervix.

\section{Abbreviations:}

PAP- Papanicolaou

ASCUS - Atypical squamous cells of undetermined significance

ASCH - Atypical squamous cells cannot exclude HSIL

LSIL - Low grade squamous intraepithelial lesion

HSIL - High grade squamous intraepithelial lesion

SCC - Squamous cell carcinoma

NILM - Negative for intraepithelial or malignancy

\section{References:}

1. Ferlay J., Shin H.R., Bray F., Forman D., Mathers C., and Parkin D.M. et al. Estimates of worldwide burden of cancer in
2008: GLOBOCAN 2008.International Journal of Cancer December; 127 (12),2893-2917, 2010.

2. National Cancer Regitry Program. Annual Report. IC New Delhi; 1990-1996.

3. Sreedevi A, Javed R, Dinesh A. Epidemiology of cervical cancer with special focus on India. Int J Women's Health 2015;7:405-14.

4. Shekhar H, Pancharia A, Chauhan S, Kaur A, Chauhan S. Cytological pattern of cervical Papanicolaou smear in Rajasthan: a screening and diagnostic procedure. Int J Dent Med Res 2014;1(3):1-7.

5. Maryem A., Ghazala M., Arif, H.A., Tamkin K.-Smear Pattern and Spectrum of Premalignant and Malignant Cervical Epithelial Lesions in Postmenopausal Indian Women: A Hospital Based Study. Diagnostic Cytopathology; 40(11):976-983,2011.

6. Bodal VK, Brar RK, Bal MS, Kaur B, Kaur S, Suri AK, et al. Correlation of Pap smear with histopathological findings in malignant and non- malignant lesions of cervix. Global Journal of Medical Research. 2014;14:19-24.

7. Hande Celik Mehmetoglu, Ganime Sadikoglu et al. Pap smear screening in the primary health care setting: A study from Turkey. $\mathrm{N}$ Am J Med Sci. 2010;2:1-28.

8. Ashok Verma *, Suresh Verma, Shivani Vashist, Sumit Attri, Amrita SinghalA study on cervical cancer screening in symptomatic women using Pap smear in a tertiary care hospital in rural area of Himachal Pradesh, Indiahttp://dx.doi.org/10.1016/j.mefs.2016. 09.002

9. P. Vijaya Lakshmi, S.R. Sree Gouri. Study and analysis of two hundred cervical PAP smears in our hospital. International Journal of Contemporary Medical Research 2016;3(9):2787-2789.

10. Patel PCB, Shah PC, Bhagat VM. A role of cervical Pap smear as a screening tool in diagnosis of lesions of cervix - a one-year study. Int J Med Sci Public Health 2016;5:1841-1845

11. Sunita A. Bamanikar, Dadaso S. Baravkar, Shirish S. Chandanwale, Prachet Dapkekar, 
Dr. Priya Vijaykumar Gameti et al, International Journal of Medical and Biomedical Studies (IJMBS)

Study of Cervical Pap Smears in a Tertiary Hospitallndian Medical Gazette - JULY 2014 Mandakini M Patel1, Amrish N Pandya1, Jigna Modicervical Pap Smear Study And Its
Utility In Cancer Screening, To Specify The Strategy For Cervical Cancer Control2 National Journal Of Community Medicine 2011 Volume 2 Issue 1 